\title{
Jaber: Reflections on a Luo Aesthetic Expression
}

\author{
Odoch Pido \\ Department of Design and Creative Media \\ The Technical University of Kenya, Kenya \\ odochpido@gmail.com
}

DOI: http://dx.doi.org/10.4314/tp.v7i1.6

Thought and Practice: A Journal of the Philosophical Association of Kenya (PAK)

New Series, Vol.7 No.1, June 2015, pp.103-122

thoughtandpractice@gmail.com

http://ajol.info/index.php/tp/index

ISSN: 2076-7714 


\begin{abstract}
As a common expression, the Luo word jaber seems to be ordinary or even casual, yet it is a capsule of profound ideas within the context of Luo aesthetics. Jaber literally means "a person of beauty": it is often used to describe females who have exceptional physical qualities that make them outstandingly attractive and deeply pleasurable to look at. The article advances the view that the term jaber offers us a key to understanding the aesthetics of the Luo of Kenya and of Western Nilotic-speakers in general.
\end{abstract}

The author drew from personal experience, informal interviews, unpublished songs and existing literature as a basis for description and analysis of jaber. The picture that emerged suggested that visual beauty is only one layer of the meaning of jaber. Exploration of other layers and meanings in a broad context revealed that the expression points to aesthetic ideals, and can therefore be regarded as artistic. Dholuo speakers use the term to express appreciation of what they see, hear and feel; but it is also an intellectual tool used to offer a critique of concrete and non-concrete objects. The article is a contribution to the discourse on East African aesthetics.

\title{
Key Words
}

Jaber, beautiful, aesthetic expression, verbal communication, Luo

\section{Introduction}

In this article, I attempt to contribute to a deeper understanding of East African aesthetics ${ }^{1}$. Towards this end, I examine the Dholuo expression jaber $^{2}$. I draw largely from existing texts and ethnic expressions of the Luo of Kenya and the Acholi of Uganda. To understand the depth and complexity of meanings that jaber evokes, I look at its history, cultural underpinning and connections to characteristic Luo behavior. I also focus on its semantics as illustrative of how we, Luo speakers,

\footnotetext{
${ }^{1}$ Aesthetics is the sense of what is good, proper, right and truly beautiful.

${ }^{2}$ Jaber is a Dholuo term normally used to refer to a physically, behaviorally and spiritually beautiful lady.
} 
undertake critique of concrete and non-concrete forms. The term jaber has its lexical root in the word ber (good, right and beautiful), which has a wide range of literal and metaphorical meanings, some of which are considered here. Following general description, I move onto social and cultural contexts, intrinsic and plastic beauty, as well as aesthetic discussions. I conclude by offering some suggestions on the way forward in studying East African aesthetics.

The Luo people are Nilotic-speakers who live in Western Kenya around Lake Victoria (Miruka 2001, 1). Their ethnic relatives are in Tanzania, Uganda, the Democratic Republic of Congo, Sudan and Ethiopia (Ojwang 2007). These peoples include the Acholi, Langi, JoNam, Padhola, Oboo and Anuak. The origins of some of the names seem obvious; for example, JoNam means "people of large bodies of water", as may be seen in lakes and big rivers. Anyuak is possibly abbreviated from a nywak kwedi ("let me share with you", as in sharing the route with another traveler). However, the origin of the term "Luo" is not yet clear, although some people suggest that luwo (literally "to follow", as in migration) gave birth to the term, which is used to refer to both the people and the land. For the purposes of this article, I adopt luwo; in any case, to fully discuss the origin of the Luo and their settlement in Western Kenya is well covered in many publications, most notably by Bethwell Ogot (1967).

One of the oldest lessons in school is that "Art is man-made"; yet jaber is not a thing of the school, and neither is it exactly man-made. In general, trying to see jaber as Art through the lens of non-African art history is unlikely to be very fruitful because it is not rare, not one of a kind, and is "uncreative" (Mead 1971, 136) in that it has no "eureka response" to it. Some European art historians prefer to see Art as a deep intellectual commitment, scientific indulgence and expression of utopian ideas about tomorrow. Whereas jaber is an intellectual engagement, it is current rather than futuristic, and practical rather than utopian. These European lenses do not often focus on East African concepts of Art as attached to and acted out by the human body and mind (Abiodun 2001). Regardless of other views, I think that jaber is an aesthetic expression because it concerns consensual notions of quality (Thompson 1971, 374), while fulfilling expression and communication needs (Sieber1971, 128). In the East African context, this is arguably Art because it is like a spoken and acted-out insight 
bringing together both concrete and abstract elements to form a unified and beautiful whole.

If there is anyone wondering what prompted the writing of this article, here is the story of a social blunder that I once made, and that triggered the curiosity that has eventually led to it. On that day, at tea break in the café at my then place of work, I addressed one of two female colleagues as nyako ${ }^{3}$; the colleague had just defended her doctoral thesis. The other female colleague took exception to my use of nyako to address our colleague: I think she mistook my address for a deliberate attempt to slight her friend who deserved a more complimentary address. On realizing that I had blundered, I sought to know respectful ways to address ladies of her stature. I learned that jaber is one way of doing so. This led me to a great deal of reflection on the term. Thereafter, I conducted many interviews and informal discussions around the subject. Recourse to existing literature revealed how sparsely scholars had written on East African aesthetics. Consequently, there is much room for closer scrutiny of jaber and other everyday expressions. I therefore hope that the present article helps to shed more light on the richness and complexity of meanings in East African languages, and on how their owners interact with one another to create the human as a work of art.

As in other parts of the world, we in East Africa often hold similar aesthetic views despite apparent differences. Like the Kikamba words mwende, mwendwa and mwenda ${ }^{4,}$, jaber is often more spoken than written. In Kikamba mwende stands for anything beloved, including a beautiful and lovely lady, while mwendwa and mwenda stand for a sweetheart. Omulayi is the Luhya equivalent of jaber - a female who is not outstandingly beautiful, but is proper and lovely enough to be a wife. Among the Maasai of Kenya and Tanzania, entito eshilo refers to a lady who is wholesome, virtuous, beautiful and as endearing as jaber. In the Buganda Kingdom of Southern Uganda, salongo fondly refers to a mother of twins. In this cultural province, salongo paints a picture of a great, powerful and productive woman: she is a full woman and beautiful at the level of a king's wife. A Muganda young girl usually aspires to be the

\footnotetext{
${ }^{3}$ Nyako literally refers to a girl, but it also refers to youthfulness, invincibility, or something "evergreen".

${ }^{4}$ Kikamba is the language of the Kamba people, living in Makueni, Machakos and Kitui counties in Kenya.
} 
wife of a "king" - a queen of sorts. A wife in such a "palace" has attained the highest level of womanhood and a sense of womanly beauty. It is understood that some Baganda men do not mind when their wives have sexual intercourse with the $K a b a k a^{5}$, as doing so certifies them as full women with sensuous beauty of the kind associated with jaber.

With regard to Swahili aesthetics, Farouk Topan speaks about the notion of uzuri as being good, beautiful and wholesome (Topan 2008, 89) while kazuri means small and beautiful. In the same vein, Abdela begins with the expression "I am like a Khanga Cloth, I Die in all my Beauty" (Abdela 2008, 99). Like Topan, Abdela does not fully discuss the Swahili concept of beauty, yet the Khanga wrapper is very popular among the Swahili and throughout East Africa. However, discussions with Swahili speakers, historians and anthropologists indicate that women used to tie the wrapper around over-sized-skirts, making their buttocks standout, similar to the back of the kahanga (guinea fowl), a bird that locals considered to be very beautiful. Swahili women with big buttocks are seen as beautiful; this is why women are just too happy "strutting the stuff" (Oloruntoba-Oju 2007). In West Africa, Onayemi (2004) speaks of the concept of female beauty, and sections of his work are in tune with concepts of beauty in East Africa.

As the foregoing brief survey indicates, exploring similarities in aesthetic concepts in East Africa is tempting because it promises to yield rich insights. However, let me return to the Luo jaber. In Song of Lawino, Okot p'Bitek distinguishes modern from traditional beauty; the latter is my concern in this article, since I see jaber in the context of traditional beauty moved into the so-called modern context. In general, p'Bitek's Song of Lawino depicts an Acholi beauty as someone young, warm, strong and agile, with a smooth and shiny skin, not foolish, and not shy (p'Bitek 1972, 3847). In Ber Wat ("The goodness/Beauty of a Relative"), Grace Ogot (1998) discusses beauty as experienced with relatives, which is apparently different from beauty experienced by people in love.

\footnotetext{
${ }^{5}$ Kabaka is the term used to refer to the King of Buganda in Uganda.
} 
As a precursor to examining jaber, I reflected on my own Acholi culture, where the cognate of jaber, namely, laber ${ }^{6}$ is similar in meaning and usage. The examination of my Acholi cultural experience revealed that jaber is used in a number of different ways. In one context, jaber is used to hurl insults at "the other woman"-a common practice among women intensely competing for a lover or husband. It is not yet clear whether or not a husband also insults "the other man", but it is evident that a man often uses jaber to refer to the woman of his love.

The meaning of Jaber seems obvious and not worthy of much discussion; but the curiosity-sustaining questions were "Who is or is not jaber, and what does it mean or not mean to a Luo and a scholar?" My colleagues at the University of Nairobi and I discussed jaber and made plenty of jokes about who is or is not and who should or should not be referred to by this term. Jokes aside, such discussions enabled me to see that "what is not" often tells a great deal about "what is"-the negative sheds light on the positive, ugliness illuminates beauty, "back" gives insight into "front", "short" into "tall", and "fat" into "thin". Thus on the whole, it seems that "mitigation" is a significant aspect of Luo and the greater Nilotic-speakers' sense of true beauty. This is why the Acholi say "laber ume ngwee (the beautiful one has a smelly nose)."

\section{Social and Cultural Contexts}

An excellent history of the Luo of Kenya and the Acholi of Uganda, and of their places in the greater community of Lwo speakers, is to be found in the works of Bethwell Ogot (1967), Onyango-Ogutu and Roscoe (1974) and Ochieng (1974). However, the works of the scholars I mention here are only part of the broader picture, in that they do not include much oral history. To tell what I know from my own experience as a member of the Acholi community of Uganda who has also deeply interacted with the Luo of Kenya, I begin with Lamanyago, my maternal granduncle, who was a petty trader. We children in the family believed he visited Kisumu several times to buy flywhisks that he later traded for goats, sheep or cattle and became a wealthy livestock owner. My grandfather told us the story of my grand uncle's journey and the Kenya Luo. From his story I learned that the Luo are friendly

\footnotetext{
${ }^{6}$ Laber is an Acholi word for a woman of classic beauty.
} 
and easy-going; the characteristic Luo outlook provides a social environment in which jaber ("beautiful personhood") flourishes.

Relatives working in Nairobi and Kisumu told us about the Luo. At that time, the 1950s, we children admired those in wage-earning employment because we believed that they had money, although we had only ill-informed, vague and rather fancy ideas of what money was worth. We always crowded around wage earners to study them, to hear their stories and to learn about things lying beyond our horizons. From the wage earners I gathered that the Luo arewade $e^{7}$ meaning that they are warm and welcoming people: as far as the Luo are concerned, to behave warmly and in a welcoming manner is to be jaber, that is, beautiful in a non-plastic sense of beauty.

Between 1962 and 1966, my age mates and I attended Teso College, Aloet, a secondary school located near Soroti in Teso Sub-Region of Eastern Uganda. I joined the school's mountaineering club because it was the way we young school-goers were able to undertake adventures as big as climbing mountains. One weekend we left school, headed for Mount Elgon and embarked on climbing it, with Jackson Peak as our destination. On reaching the third and last camp, we took a break and stayed the night. It was on that night when a fellow student told us that Oginga Odinga had declined political independence for Kenya as long as Jomo Kenyatta and other political activists remained in jail. We could not help getting impressed with Odinga and his entire Luo community for being mindful of fellow Kenyans. We students considered Odinga and his Luo people to be jobeyo ${ }^{8}$ (mindful of other people's welfare)as is the case with any community that is kind, well behaved and considerate.

It was when I joined Nairobi University College in 1968 that the term wuodthuon ${ }^{9}$ first struck me, because it was on many Luo lips. Wuodthuon was how Luo students addressed fellow students of Luo/Lwo origin, negotiated social relationships and became friends and equals. In my estimation, jaber is also a way of negotiating relationships, as it evokes a good feeling - it is about youthfulness, invincibility and

\footnotetext{
${ }^{7}$ Wade or wede refers to blood relatives or life with and among relatives.

${ }^{8}$ Jobeyo is the plural of jaber.

${ }^{9}$ Wuodthuon literally means "the son of a bull of a man", that is, a brave and powerful man.
} 


\section{Odoch Pido}

friendship among equals. This term of address reminded me of nyingthuon or oxname that a Dinka man gives to his ox and uses it to praise himself (Burton 1980, 27). In some Lwo communities, self-praise is considered to be recklessly ambitious, unthinkable and "fondling the ball of supernatural powers", that is, playing with super-human danger. This is why self-praise is often discreet and indirect. Instead of praising himself, a man praises his bull and celebrates his prowess without annoying powerful and damaging spirits of his immediate and distant ancestors.

Whenever bulls met at the grazing ground, they fought for their own animal reasons; but Luo people see bullfights as fights between bull-owners, their friends and their clans. Even when two bulls do not want to fight, they will be induced to do so. Bulls are cajoled to fight because it is seen as a kind of high-octane spectacle, a type of sports where bulls win but bull-owners appropriate the victory for themselves, as if "sweet victory" is not for beasts. Of course, the bull that loses the fight is driven away; this is often when owners and their associates set upon each other and serious stick fights ensue. There is no reason to ask why the Luo resort to fighting because fights are taken for granted; however, it seems fighting is a way of healing bruised egos. To see similarities between jaber and bullfights, one must remember that getting a jaber is often a great struggle: any man who gets her often experiences a similar sense of "sweet victory"; and the man who fails to get jaber often resorts to fighting as a way of dealing with failure, frustration and a bruised ego. In order to remain a jaber, a lady protects her ego: situations that deflate the ego are never forgiven because they are considered to be dehumanizing. Addressing a lady as nyarthuon ${ }^{10}$ is to stroke her ego and to make her feel good (feel on top of the world and as beautiful as jaber).

When we were undergraduate students at the University of Nairobi, I could not ignore the term omin ("brother") because it was frequently used by Luo speakers. In any case, it made me feel at home since it accorded me a sense of social security. Omin is a male with whom you metaphorically share a mother's womb, a symbol of life in brotherhood. The Luo cultural sense of a mother seems to be more than physical: it is what binds persons together as one people in body and spirit, and therefore in joy and

\footnotetext{
${ }^{10}$ Nyarthuon literally means "the daughter of a bull of a man", that is, a great and powerful man.
} 
sorrow. On the other hand omera is a bosom male friend, while ominmara ${ }^{11}$ expresses a deep and affectionate sense of relationship. Omin, omera and omin mara speak of male-to-male linkages in social-cultural spaces in which life is beautiful, habitable and enjoyable.

In the Kenya of the 1960s, soccer was very popular and an avenue for expressing ethnic affiliation. I could see "soccer blood flowing in Luo veins", and the football club Gor Mahia ${ }^{12}$ was the heart. Gor Mahia supporters went to a soccer match to cheer their team to victory, and were clear that "either the other team had to lose or Gor had to win". While they mourned the loss of matches on the streets and elsewhere, they profusely celebrated victories: partying often went on in residential estates, especially the Nairobi estates of Jericho, Ofafa and Kaloleni. Luo celebrations were for all, including passers-by. The all-inclusive partying is how I came to know that the Luo are generous and not obvious class snobs: generosity and respect for all are parts of the people's aesthetics. I also learned that jaber-style life is about equitable distribution, as well as being generous and celebrating life without reservation.

I have much to say about my experiences with things Luo, but let me end my outline of the socio-cultural context of jaber with another manifestation of Luo aesthetics, namely, nyadhi ("befitting finesse"). During the famous legal tussle between S.M. Otieno's widow, Wambui Otieno, and the Umira Kager clan, I was branded a JaLuo who should never try to marry a Kikuyu girl because Luo cultural practices, especially death rituals, are primitive and misogynist. Since I had a Kikuyu girlfriend at that time, I was not happy with the comment because I thought it was a direct intrusion into my personal affairs. As an outsider and one not too intimate with Luo-Kikuyu interactions, I was surprised. I also felt that those who accused the Luo of denying Wambui her rights probably missed something dear to the Luo, especially the people of Umira Kager. The accusers failed to see that the people of Umira Kager, Otieno's clan, wanted to bury their son with nyadhi- a practice that bestows great honor to the burial of someone highly respected in the community. The practice has the homestead

\footnotetext{
${ }^{11}$ Omin mara means "my brother".

${ }^{12}$ Gor Mahia is the name of a soccer club dominated by the Luo; it represents a mystical, miraculous and powerful spirit; the origin has to do with Kanyamwa in Ndhiwa Constituency in Homa Bay County.
} 


\section{Odoch Pido}

and its spirit centered in Nyalgunga, S.M. Otieno's ancestral home, instead of a house in Upper Matasia on the Eastern slopes of Ngong Hills 400 kilometers away. ${ }^{2}$ The homestead (dala) is the place for the dead, living and not-yet-born relatives. Nyadhi finds links with today's jaber, since with regard to jaber a person dresses up and does all that he or she can to be proper hoping to impress a person of the opposite sex.

\section{Intrinsic and Plastic Beauty}

Whenever one says that ngat no rac ("that person is bad"), one implies that she is physically ugly and behaves badly. However, a discussant from South Nyanza is of the opinion that no Luo woman is ugly because every woman finds a husband. That there is no ugly woman in Luo land suggests that ber mar kido ("beauty of character") is important and often preferred to physical beauty. This is why a physically ugly woman is beautiful as long as she is a good wife and a good mother. At the same time, a physically beautiful woman who is unfaithful or is a poor mother can be seen as ugly (Crowley 1971). The Luo say dhako ber gidi chuo ("a woman is beautiful only with a husband"): this is so because the man "completes" the woman. A man is also beautiful only with a wife because a woman "completes" a man.

A woman can, but does not often publicly address any man as jaber, for it is viewed as seducing a man by force - desperately wanting a man - and that is considered to be morally reprehensible. Instead of seducing men openly, women often indulge in nuances to get men they like. In private, a woman can refer to her lover as jaber; or when discreetly talking about someone else, she can say "nyane oyudo wuowi ma jaber" (she found a handsome man). A man can claim he is jaber when he wants to feel good about himself, to show-off or to demonstrate his dominant character(Ogola 1994, 21). At times to address a man as jaber is like calling him sissy, insulting his manhood and inviting physical squabbles. A traditional Luo woman is not jaber to another woman because they say," a cow cannot climb a cow"12. However, young females in Nairobi are known to refer to their best friends as jaber: this Westernized

\footnotetext{
${ }^{2}$ During the famous court case, no one mentioned the general East African requirement to 'follow suit'. This meant that if the first born was not buried in the ancestral home, none of his junior brothers could be buried there, and the family and the clan would die out.

12 "A cow cannot climb another cow" means "a woman cannot mate with another woman".
} 
practice is merely a show of intimate friendship and an acknowledgement that the friend is "well turned out".

Furthermore, a father can address his young daughter as jaber, but stops referring to her as such when she reaches puberty: referring to a teenage daughter as jaber can be mistaken for breaking kwero (taboo) leading to chiraa $^{13}$. A mother is not jaber to her son. It is rather interesting to note that a grandson can refer to his grandmother as jaber because he "jokingly" sees her as his wife; for the same reason (of generation alternation), a grandfather can refer to his granddaughter as jaber. In general, a female is jaber to a man when the two are falling in love. To refer to a stranger as jaber amounts to saying that she is of loose sexual conduct. Whenever a strange man addresses a female as jaber, she responds in a characteristic Luo style of keeping quiet as if she did not hear him speak, thereby indicating that she is not interested in his advances. He must persist and show commitment before she seriously considers his advances; thereafter, she might become willing to be his jaber, that is, to be loved sensually by him.

It is useful to give an outline of how we, Acholi children, learned the characteristic Luo senses of plastic and intrinsic beauty. At about one year of age, we learned to speak, and "mother" was one of our first words. Within a short time" mother" was synonymous with milk, food, and a source of comfort, pleasure and a sense of beauty. At this level we were not yet finely tuned on differences between our mothers and other people. Oblivious to the distinctions, we sometimes grabbed men's breasts hoping to find milk and to suckle, only to cry in disappointment. From the disappointments we learned that some breasts "have no milk" (they were not beautiful), and that unfulfilled expectations were also not beautiful. Becoming adults did not obliterate beautiful memories of our mothers' milk: the breast continued to be a symbol of love between mothers and their children.

\footnotetext{
${ }^{13}$ Chiraa is a powerful ancestral curse brought on by misconduct. Though it can be incurred for a variety of unacceptable forms of behaviour, and is not necessarily vented on the same family member who committed the offense, it is generally of a sexual nature. The Dholuo word chiraa is related to the Swahili verb kuchira which refers to parents who wrongfully resume sexual relations before the end of the two year post-partum sex taboo.
} 


\section{Odoch Pido}

From singing and playing with home-made toys I learned to live in harmony with other children and with the world around me. I also learned that a life of harmony rather than conflict is beautiful (ber). Instruction from adults was another avenue for learning as we grew up: we received instructions on how to distinguish between what is safe and what is dangerous, between what is good and what is bad. In a situation where naked fire was all there was to cook and keep warm, we needed to get it straight and early that fire was dangerous. To drive this lesson home, a child was given fire to touch. The child got a slight burn and cried in pain; the deliberate burn sounded cruel, but the lesson was never forgotten, and this for good reason. In our adulthood, whenever anybody says a woman is lyet calo mac ("hot like fire"), we immediately get the two contrasting sides to the statement. On the one hand, it means that she is "smashingly beautiful" - so beautiful as to be comparable to the intensity of fire; on the other hand, it means that she is uncontrollably quick-tempered, abrasive and not jaber.

We left mother's milk and went onto drinking goat milk. For us, cattle keepers, men milked cattle every morning and evening while women milked goats. Ignoring the fact that we did not possess the required skills and muscle power, we were deluded into thinking that milking goats was easy enough for us to undertake. We tried to milk them, but did not get any milk; instead we got kicked, hurt and cried for help from anyone who cared. However, those on the scene neither showed sympathy nor rescued us from the ordeal. The lack of sympathy and help taught us a few lessons. One of the lessons relevant to this article is that nice things, including beautiful women, are difficult to get; indeed, getting a jaber is no easy matter, and sometimes one must travel the road alone.

There are many other jaber-related lessons that we learned as we grew up. For purposes of this short article, let me turn to how I learned to tell a lady who is jaber from one who is non-jaber. When we were about five to ten years old, we played a game called dinidini Lango obino ("children, children! Lango the enemy has come"). The game was one way of learning that life is good with spouses. During this game each one of us was challenged to tell who was his/her wife/husband. It was impossible for me to say who was my wife because marriage was well beyond my social horizon. After persistent persuasion, I declared that one of my aunties was my wife, causing 
hearty laughter, signifying that I got it wrong because wede (relatives) are not sensual jobeyo (plural of jaber").

During my early teens, my maternal uncle kept asking me whom I would marry if marriage were forced on me at that time. I thought he was joking, but he reminded me that he was serious because my marriage was his responsibility, and he needed to begin participating in courting my wife-to-be. Convinced he was not joking, I chose a girl I thought had a wonderful smile and a big body. At that time a heavily built girl was considered to be beautiful because large size signified the ability to win quarrels and fights: I saw her as a promise of big and strong children who would ensure my family's security. To me, a good smile and big body meant that she was generous and easy-going, so that life with her as a wife would be fun. However, my uncle rejected my choice, explaining that the girl was rabbet (massive) and therefore unable to withstand the rigors of marriage. In addition, such a fat girl is considered to be uninviting and not really jaber.

I abandoned my first choice for another girl who was slender and rather shapely. Although she was more or less the opposite of my first choice, my uncle rejected her too for the reason that she had a bad side to her. The good side was that she was lanede (flat around the belly as if without guts), which is seen as very beautiful and an excellent choice. In general, lanede gives the impression of someone who is not crazy about food, one who is strong-hearted, able to survive disaster, and dependable when times are miserable. However, her hair was light brown, suggesting that she suffered from kwashiorkor, which would mean that she grew up unhealthy and weak. My uncle did not want me to bring a weakling into the family, as doing so might contaminate our strong family gene. The little bad element in her negatively affected the "total score" of the girl I saw as jaber and wished to marry.

Although I was beginning to feel that my uncle was determined to disagree with all my choices, I made a third choice of a girl whose waist was as thin as that of a hornet - a "wasp waist". I saw her as lamuya (a bird species known in English as "cape glossy starling”), but her skin was matte black: even her fingernails tended towards 


\section{Odoch Pido}

blackness, and she had reddish eyes. She was as polite and soft-spoken as jachia ${ }^{13}$. I expected my uncle to applaud my third choice but he did not, explaining that she was too dark and matte, not shiny. A woman that black would get offspring with baboonlike palms and nails - not good. He also complained that she resembled the crow more than the starling, meaning that she was not beautiful. He also said that her matte skin and reddish eyes were signs of health gone wrong early in her life. However, his biggest objection was that her waist was too thin, and such women were known to die at the time of giving birth.

My fourth choice was rapudo ${ }^{14}$, with white teeth, brown shiny skin and sparkling eyes: again, my uncle rejected her on the grounds that her eyes sparkled. He said such sparkling eyes was a sign of evil in her eyes. My head started spinning, wondering why my uncle seemed to dislike every choice I made. I asked one of my aunties to explain why he was behaving like that. She explained that he was merely letting me know the qualities of a truly beautiful woman - the best candidate for a wife. At the same time, he wanted me to know that no one is spotlessly beautiful - that even the beautiful one has something not-so-beautiful about her. Contradiction and mitigation are important elements in the appreciation of a beautiful lady in the sense that a little bit of her is expected to be ugly. One hundred percent beautiful is neither expected nor acceptable: it is actually considered to be ugly.

\section{Aesthetic Discussions}

A literal translation of jaber is a person of true beauty including good, proper and pleasant appearance. Although it is often seen in the context of plastic, romantic and sexual beauty, jaber is more than a beautiful-looking female. To look beautiful generally positions a girl at the center of male attention and female jealousy; she is in a position to pick and choose a spouse. She is the kind who is likely to be jaber jaula ${ }^{15}$, or she is the queen who makes wuodthuon (literally "the son of a bull") weep. Whatever the reason for tears, practically every Luo woman tries her best to dress up

\footnotetext{
${ }^{13}$ Jachia is another word for jaber, and is commonly used by the Luo of South Nyanza.

${ }^{14}$ Rapudo is used to describe a lady who is just right, neither too tall nor too short, fat but thin at the same time, and black but not too black.

${ }^{15}$ Jaberjaula describes a woman whose beauty has gone to her head: she is spoilt.
} 
and appear attractive to men. To be attractive implies looking new, fresh, unique, loud and catchy. No doubt debates have been raging on whether or not "attractive" and "beautiful" are synonymous.

It is important to note that In Luo thought, expressions of beauty frequently emphasize parts of the body rather than the whole of it. The parts of the body influencing verbal expression of aesthetics include the eyes, teeth, neck, buttocks and hands, which are often likened to animals, stars and birds. White eyes that contrast with a face of blue-black skin is seen as beautiful. In speaking to a jaber, a man can say, "Your eyes are as eyes of fish in fresh water"; this expression discreetly speaks about the ideal proportion of form and color, highlight or a point of intense interest: all these are qualities of beautiful objects. When a female has eyes as red as those of a tilapia, her beauty is considered to be superior to that of one with white eyes because we all yearn for something unique. In addition, red exists in opposition to black: opposition accounts for beauty in man-made objects (Klumpp 1987).

Of a woman with excess appetite for sexual intercourse, the Luo say that her eyes glitter or wange dongo kawang kwach ${ }^{16:}$. Although there is no sharp line to separate small and big sex appetite or correct and incorrect sexual behavior, ideally jaber is morally upright and has a moderate sex appetite. Whether or not her eyes glitter, jaber does not look her spouse in the eye especially in public: to do so is as disrespectful as washing dirty linen in public. Looking at a spouse in the eyes is seen as sexually too aggressive. These and more examples show that qualities of the eyes or sight can enhance or diminish a girl's beauty.

In appreciating the beauty of jaber, an admirer may say, "her neck is as long as the neck of the crested-crane." The neck of the crested crane is long, supple, not straight and stiff, and with a crown at the end. Assuming that a woman's hair is her crown, one can see why Luo speakers chose the crane over other birds with equally long necks but without the crown. Nevertheless, there is the matter of Udo (ostrich) - a name given to a girl on account of her long and naturally ringed neck. Whereas beauty in women is often likened to the beauty in the ostrich and other birds, aggression is

\footnotetext{
${ }^{16}$ Wange dongo ka wang kwach literally means "her eyes are as big as those of a leopard".
} 


\section{Odoch Pido}

also admired: this may explain why some males and females are named Kwach and Lakwach ("leopard"), respectively. In other words an aggressive lady can be jaber: here the sense of beauty derives from contradiction, in that beauty with a little badness is truly beautiful.

I want to reflect on the meaning of the Acholi expression ber pa lalaa ${ }^{17}$, as it can help to shed light on the Luo understanding of sexuality in general and of jaber in particular. At the metaphorical level, the expression makes a statement on beauty intended for the eyes only - to be seen: the Luo hardly appreciate this type of beauty. An ideal Luo beauty is expected to accept no other man but her husband as her only man; otherwise she is jaber jaula (a lady whose beauty attracts many men who contaminate her sexual morals). She is expected to work the fields to produce food crops, otherwise she is jaber puothe (literally "the beautiful one of gardens"), meaning that she is too full of herself to have time to work, so that she does not even have a small garden. To get a better appreciation of the expression, one must bear in mind that in Luo culture beauty without food is as meaningless as beauty without life.

Finally, the Acholi ber pa lalaa is the equivalent of the Dholuo bernono ${ }^{18}$ (one who looks beautiful but nothing else is beautiful about her). This implies that looks alone do not constitute true beauty. This translation also places emphasis on the view that a beautiful woman gives birth to a child: she is ber nono if she remains childless. The craving for children stems from the desire for continuity: the Luo believe that a child continues to live for his or her parents after they have died. The idea of symbolically continuing to live after death is highly valued among the Luo and throughout Africa. For example, the Akamba of Kenya dread a childless marriage so much that they refer to it as permanent death; in such a case the affected wife can "marry" another woman who gets children with her husband on her behalf.

Romance made in Europe (spoken, openly displayed and with no distinction between gender roles) is a recent phenomenon among the Luo. Traditionally, Luo romance is discreet in thought and action. Jaber is a woman who loves her husband without

\footnotetext{
${ }^{17}$ Ber pa lalaa is the beauty of the lalaa plant: it looks beautiful but tastes nasty.

${ }^{18}$ Bernono stands for meaningless beauty.
} 
indulging in speaking about the quality and quantity of her love. To demonstrate her wit, agility and physical prowess, she takes a big container with which she fetches water from the stream, cooks a good meal and brews alcohol that elders enjoy. Jaber works hard in order to take good care of children (her own and those of the entire homestead or village). In many cases, she is also intelligent and an important advisor to her husband and other men in the home and village.

Of jaber the Luo say, "she has a handful of buttocks", meaning that she is plump. Americans, in particular, do not like a fat woman because she gives the impression that she is careless and eats uncontrollably. Unlike Americans, the Luo prefer fullfigured women because their appearance is evidence that they are not mean and miserly; they are well bred in homes with plenty to give. A slim woman is seen as evidence of poor health emanating from drought and food shortage, excessive manual work and a difficult marriage. This is why a fat woman portrays a good life. A fat wife is an indication of a caring husband: his family appreciates her and treats her well. In addition, people believe that fat women do not experience birth-related difficulties. Few childbirth complications mean high rates of survival for both mother and child. Overall, a fat woman is seen as jaber. Spotting long and slender fingers suggests that she is gentle, able to take care of babies: they are like the icing on the cake. Classic Luo beauty includes a lady who is nyalando (chocolate brown) and ragwel (bow-legged). Why a Luo finds chocolate brown and bow-legs beautiful remains unclear, but one cannot help noticing that brown and bow-legged ladies are few among the Luo.

To earn the pronouncement ber kanyar jajuok ${ }^{20}$ is to be bewitchingly beautiful. It is to be slender and proportionally built, not so thin yet not so fat, neither too short nor too tall: these features of body weight, height and shape raise curiosity on exact instead of approximate measurements. Jaber has well-shaped legs that people would want to borrow if they could, just to show off. Good shape is part of the core of the Luo sense of beauty located in round firm breasts (Ogot 1998, 59). It seems that Luo beauty is not a subject of fashion: fashionable adornment may add to it, but lack of such adornment cannot erase it.

\footnotetext{
${ }^{20}$ Ber ka nyar jajuok means "as beautiful as the daughter of a witch".
} 
A woman with a voice that is so sweet as to sing like a finch earns the title of jaber. In addition, a lady is considered to be beautiful when wange chuore ${ }^{21}$. Smiles, graceful conduct and similar attributes seem to contribute to being jaber. A smile is better with mbanya (a gap in the middle of the upper front teeth), with an effect reminiscent of a beauty spot on the face or the highlight in a painting. In addition, when she walks as gently and majestically as the crested crane, or when she is swift like a swift, she is truly beautiful. People do not like women who are slow like a snail or those who are too fat and can only turn at angles as obtuse as a hippopotamus does. A slow-moving lady signals that she is lazy - a very undesirable quality because it has a negative impact on the survival of the community as far as the promotion of food security is concerned.

\section{Conclusion}

In sum, jaber is an expression of aesthetic complexity having varied meanings and contexts. At the casual level, it seems to be concerned with sexuality - how to be sexual and live sexually within the socio-cultural milieu. Among the Luo, to be sexually active is important because it is the path to getting children who symbolically perpetuate their parents' lives beyond their (parents') graves. To be childless generates a sense of doom for the family. This is why a female tries every possible means to be jaber-attractive, sexually appealing, with a view to baring children. Whenever nature stands in the way, adoption is undertaken to secure a sense of having a child. Adoption is seen as "giving birth from the side". A man who knows that he is not able to father a child allows his wife to "walk with" 22 another man who may be a brother, cousin or close friend.

Though it is only one word, jaber is like poetry serving to negotiate social relationships. When a man addresses a woman as jaber, his goal is likely to be courtship, marriage and family. Besides, there is no divorce among the Luo: even death does not "do us part". This is why a man is allowed to bury is wife even though he and she may be living separately at the time of her death. A wife is always jaber to

\footnotetext{
${ }^{21}$ Wange chuore means that her eyes dart about, sexy and irresistible.

${ }^{22}$ The phrase literally rendered here as "walk with" is a euphemism for "have sexual intercourse with".
} 
her husband, and he sees her as leng (spotless), a term that is not widely used among the Luo of Kenya, but is common among their Acholi ethnic relatives in Uganda. It implies a well-groomed body and heart that are free from any ill. In some instances, leng refers to kalando, an expression that refers to things as good-looking and chic as smart phones or sports cars; it also refers to chastity, virginity or purity.

Finally, jaber is a cultural construct that is used to make aesthetic statements about what is pleasant and desirable in life. I think jaber has to do with artistic proportion, though Luo proportion is usually based on practice and judgment instead of mathematical relationships. Jaber has to do with artistic contrast, though Luo-style contrast is only beginning to include man-made interventions, as may be seen in the use of cosmetics to accentuate beauty. As a cultural construct, a Jaluo jaber is different from beauties in other cultures of the world. Though differences in cultures do account for differences in who is or is not jaber, I propose that a truly beautiful woman has qualities that give pleasure to our senses, minds and spirits.

My primary intention in writing this article was to shed light on one aspect of African aesthetics and to generate fodder for further studies and scholarly work. In order to accomplish my goal, I draw on my cultural experience, my professional upbringing and informal discussions. At this point, I am of the view that I have only taken the first step towards explicating and reflecting upon Luo aesthetics. I think we need to cover more ground before we can draw conclusions. For example, it is important that a lady discusses jaber, since female and male perspectives of beauty are often divergent. It is also necessary for scholars to undertake studies that shed light on beauty in animals, birds, insects, vegetation and man-made objects. Parts of this work contain Acholi words that Dholuo cannot match in meanings. Assuming that Acholi and Dholuo have a common origin, it would be important to know what the migration did to Dholuo: what did Dholuo lose or gain in the migration? 


\section{References}

Abdela, Farouque. 2008. "Mimi Kama Kanga, Nafa Na UzuriWangu”. Marion Arnold ed. Art in Eastern Africa. Dar es-Salaam: MkukinaNyota Publishers.

Abiodun, Rowland. 2001. "African Aesthetics: Not a Thing for Europeans". the Journal of Aesthetic Education, Vol.35 No.4 (Winter 2001), pp.15-23. http://www.jstor.org/stable/3333783

Burton, John W. 1980. "The Village and the Cattle Camp: Aspects of Atuot Religion". Karp, Ivan and Charles S. Bird eds. Explorations in African Systems of Thought. Washington: Smithsonian Press.

Crowley, Daniel J. 1971. "An African Aesthetic". Carol F. Jopling ed. Art and Aesthetics in Primitive Societies: A Critical Anthology. New York: E.P. Dutton \& Co.

Klumpp, Donna R. 1987. "Maasai Art and Society: Age and Sex, Time and Space, Cash and Cattle". unpublished Ph.D. Dissertation, Columbia University, New York.

Mead, Margaret. 1971. "Work, Leisure and Creativity". Carol F. Jopling ed. Art and Aesthetics in Primitive Societies: A Critical Anthology. New York: E.P. Dutton \& Co.

Miruka, Okumba. 2001. Oral Literature of the Luo. Nairobi: East African Educational Publishers.

Ochieng, W.R. 1974. People around the Lake. Margaret Sharman ed. London: Evans Brothers.

Ogola, Margaret A. 1994. The River and the Source. Nairobi: Focus Books.

Ogot, Grace. 1998. The Strange Bride. Okoth Okombo trans. Nairobi: East African Educational Publishers. [Original Dholuo] 1981. Ber Wat. Kisumu: Anyange Press.

Ogot, Bethwell A. 1967. History of the Southern Luo: Volume I, Migration and Settlement, 1500-1900. (Series: Peoples of East Africa). Nairobi: East African Publishing House.

Ojwang, Humphrey J. 2007. "Language, Identity and Culture in Eastern Africa". Anyuak Media. www.anyuakmedia.com/Luo people22507.html

Oloruntoba-Oju, Talwo. 2007. "Body Image, Beauty and Language in the Nigeria, African Context". Understanding Human Sexuality Seminar Series, Africa Regional Sexuality Resource Centre, $13^{\text {th }}$ September, 2007. www.arsrc.org/downloads/uhsss/oloruntoba-oju.pdf

Onayemi, Folake. 2004. Ethnic Identity, the Concept of Female Beauty and Conflict in Classical and African Cultures. N.P.: Programme on Ethnic and Federal Studies.

Onyango- Ogutu, B. and A.A. Roscoe. 1974. Keep My Words. Nairobi: East African Educational Publishers.

p'Biteck, Okot. 1972. Song of Lawino and Song of Ocol. Nairobi: East African Publishing House.

Sieber, Roy. 1971. "The Aesthetics of Traditional African Art". Carol F. Jopling ed. Art and Aesthetics in Primitive Societies: A Critical Anthology. New York: E.P. Dutton \& Co.

Thompson, Robert Farris. 1971. "Aesthetics in Traditional Africa”. Carol F. Jopling ed. Art and Aesthetics in Primitive Societies: A critical Anthology. New York: E.P. Dutton \& Co.

Topan, Farouk. 2008. "Swahili Aesthetics: Some Observations". Marion Arnold ed. Art in Eastern Africa. Dar-es-Salaam: Mkuki na Nyota Publishers. 